\title{
Responses of the second derivative of the finger photoplethysmogram indices and hemodynamic parameters to anesthesia induction
}

\begin{abstract}
Atsushi Kohjitani ${ }^{1}$, Masaaki Miyata ${ }^{2}$, Yoko Iwase ${ }^{1}$ and Kazuna Sugiyama ${ }^{1}$
The finger photoplethysmogram (PTG) is a non-invasive method for pulse-wave analysis. The second derivative wave of the PTG (SDPTG) enables evaluation of atherosclerosis and cardiovascular aging. Responses of SDPTG indices and hemodynamic parameters to anesthesia induction are unknown. A total of $\mathbf{4 2}$ patients aged $\geqslant 40$ years, who may have had atherosclerotic change, and who underwent elective oral surgery, were analyzed. Patients were divided into sevoflurane ( $S$ group; $N=22$ ) and sevoflurane with remifentanil ( $R$ group; $N=20$ ) groups. Systolic and diastolic blood pressure (SBP, DBP), heart rate (HR) and SDPTG were measured at four time points: before induction, after loss of consciousness, after tracheal intubation and $30 \mathrm{~min}$ after induction. At postintubation, b/a was elevated (that is, large arterial stiffness was increased), and d/a was reduced (that is, peripheral vascular resistance was increased) in the S group compared with the R group. SBP, DBP and HR were increased in the $S$ group compared with those in the $\mathbf{R}$ group. In the $S$ group, preanesthetic b/a and the aging index (AGI) were positively correlated with SBP at immediate postintubation, and preanesthetic d/a was negatively correlated with SBP and DBP at immediate postintubation. It is suggested that usage of remifentanil, a potent $\mu$-opioid analgesic, with sevoflurane anesthesia prevented an increase in blood pressure and HR in response to laryngoscopy and tracheal intubation, which was accompanied by suppression of both elevation of b/a and the AGI and reduction of d/a. SDPTG indices are useful for predicting hypertension during induction of sevoflurane anesthesia, regardless of a history of hypertension or hypertensive factors.
\end{abstract}

Hypertension Research (2012) 35, 166-172; doi:10.1038/hr.2011.152; published online 22 September 2011

Keywords: blood pressure; finger photoplethysmogram; general anesthesia; tracheal intubation

\section{INTRODUCTION}

The finger photoplethysmogram (PTG) is used as a non-invasive method for pulse-wave analysis, which closely reflects pulsation of the heart. Pulse-wave analysis evaluates aortic stiffness in response to vascular aging, hypertension or atherosclerosis. ${ }^{1}$ Aortic stiffness, which is evaluated by pulse wave velocity, is strongly associated with the extent of atherosclerosis and is widely used as a marker of future development of cardiovascular complications in hypertensive patients, ${ }^{2,3}$ diabetes mellitus patients ${ }^{4}$ or even in normotensive subjects. ${ }^{5}$

The second derivative of the finger photoplethysmogram (SDPTG), or accelerated plethysmogram, is obtained from double differentiation of the PTG. The SDPTG is considered to provide structural and functional properties of both large and peripheral arteries. ${ }^{6}$ The SDPTG is effective for screening of atherosclerotic disease, such as hypertension, diabetes mellitus or coronary heart disease, ${ }^{7}$ and enables evaluation of cardiovascular aging in hypertensive patients ${ }^{8}$ by means of categorized wave patterns. ${ }^{9}$ It has also been suggested that the SDPTG is useful for estimating the risk of coronary heart disease. ${ }^{6}$
In the anesthesiology field, it is considered that the stress of laryngoscopy and tracheal intubation, which stimulate cardiac sympathetic activity and intrinsic catecholamine secretion and lead to acute hypertension and tachycardia, may be harmful to patients with cardiovascular or cerebrovascular disease, exposing them to risks of morbidity and mortality. ${ }^{10}$ For example, the incidence of myocardial ischemia is highest at the time of intubation during non-cardiac surgery in coronary artery disease patients, ${ }^{11}$ and similarly, coronary hypoperfusion has been observed at the immediate postintubation period in coronary artery disease patients. ${ }^{12}$ Furthermore, a profound decrease in left ventricular performance has been observed during reflex hypertension and tachycardia in response to laryngoscopy and intubation; there was persisting depression of left ventricular function in patients with coronary artery disease. ${ }^{13}$ Moreover, perioperative ischemic episodes, which frequently occur during intubation and surgical stimulation in response to hemodynamic abnormalities, are one of the risk factors of postoperative myocardial infarction. ${ }^{14}$ Therefore, the period during which intubation is performed is

${ }^{1}$ Department of Dental Anesthesiology, Field of Oral and Maxillofacial Rehabilitation, Kagoshima University Graduate School of Medical and Dental Sciences, Kagoshima, Japan and ${ }^{2}$ Department of Cardiovascular, Respiratory and Metabolic Medicine, Field of Cardiovascular and Respiratory Disorders, Kagoshima University Graduate School of Medical and Dental Sciences, Kagoshima, Japan

Correspondence: Dr A Kohjitani, Department of Dental Anesthesiology, Field of Oral and Maxillofacial Rehabilitation, Kagoshima University Graduate School of Medical and Dental Sciences, 8-35-1 Sakuragaoka, Kagoshima City 890-8544, Japan.

E-mail: atsushik@dent.kagoshima-u.ac.jp

Received 1 March 2011; revised 12 July 2011; accepted 20 July 2011; published online 22 September 2011 
considered to be a particularly high-risk interval, and therefore, various anesthetic techniques and drugs have been investigated to avoid hemodynamic fluctuations. ${ }^{10}$

It has been reported that preoperative SDPTG is unable to predict blood pressure (BP) increases in response to anesthesia induction in non-hypertensive patients. ${ }^{15}$ Furthermore, a recent study using preoperative carotid-femoral pulse wave velocity failed to predict hemodynamic responses to anesthesia and surgical stimulation. ${ }^{16}$ In the current study, we evaluated responses of SDPTG indices and hemodynamic parameters (systolic and diastolic blood pressure (SBP, DBP) and heart rate (HR)) to anesthesia induction. This was achieved by investigating the effect of remifentanil, a potent, ultra short-acting $\mu$ opioid analgesic that leads to bradycardia and hypotension by stimulating cardiac parasympathetic nerve and decreasing peripheral vascular resistance, ${ }^{17}$ during induction of sevoflurane anesthesia on patients aged $\geqslant 40$ years, who may have had atherosclerotic change. Second, in a sub-analysis, we investigated the relationships between BP after tracheal intubation and preanesthetic SDPTG indices (b/a, d/a and the aging index (AGI)), to determine whether SDPTG indices are capable of predicting BP in response to anesthesia induction.

\section{METHODS}

A total of 45 patients $\geqslant 40$ years old who underwent elective oral surgery were enrolled in this study following approval of the Clinical Ethical Committee of Kagoshima University Hospital. Patients were category I (normal healthy patients, no organic, physiologic or psychiatric disturbance) or II (patients with mild systemic disease, no functional limitations) of the American Society of Anesthesiologists physical status classification. ${ }^{18}$ Informed consent was obtained from all subjects. Patients were divided into two groups, sevoflurane ( $\mathrm{S}$ group) and sevoflurane with remifentanil ( $\mathrm{R}$ group), by using the random numbers table. Patients who showed unstable PTG waveforms during a $90 \mathrm{~s}$ recording period for each time point, those who showed arrhythmias such as ventricular premature beats during the recording period that altered PTG waveforms, and those who needed i.v. ephedrine because of sustained hypotension were excluded from the analysis. Patients with a history of hypertension and receiving medications for hypertension, or those with hypertensive factors were classified as hypertensive patients. The hypertensive factors were protrusion of the aortic arch into the left lung field or calcification of the aorta in a chest radiograph, left ventricular hypertrophy in an echocardiogram, or SBP $\geqslant 140 \mathrm{~mm} \mathrm{Hg}$ and/or DBP $\geqslant 90 \mathrm{~mm} \mathrm{Hg}$ after entering the hospital until the day before the operation. BP was measured at the sitting position, and the mean value of two measurements was used.
The study scheme is shown in Figure 1. Patients were premedicated with atropine sulfate $(0.5 \mathrm{mg})$ and pentazocine $(15 \mathrm{mg})$ intramuscularly $30 \mathrm{~min}$ before induction of anesthesia. Routine antihypertensive medications were continued until the day of surgery; however, angiotensin II receptor blockers and angiotensin-converting enzyme inhibitors were discontinued on the day of surgery to minimize hypotension during anesthesia. In the $S$ group, anesthesia was induced by thiopental sodium and inhalation of sevoflurane with $66 \%$ nitrous oxide in oxygen, and then tracheal intubation was facilitated by i.v. vecuronium $\left(0.1 \mathrm{mg} \mathrm{kg}^{-1}\right)$. In the $\mathrm{R}$ group, remifentanil $\left(0.25 \mu \mathrm{g} \mathrm{kg}^{-1} \mathrm{~min}^{-1}\right)$ was added immediately after application of thiopental sodium using the same procedure as the $\mathrm{S}$ group. In both groups, a total of 2.5 minimum alveolar concentration (MAC) using sevoflurane with nitrous oxide was applied until the trachea was intubated. A MAC of $66 \%$ nitrous oxide was equipotent to $1.05 \%$ sevoflurane, ${ }^{19}$ and the MAC for age of each patient was adjusted according to Mapleson's formula. ${ }^{20}$ For example, $2.5 \mathrm{MAC}$ for 60 years old requires an expired sevoflurane concentration of $4.25 \%$; when adding $67 \%$ nitrous oxide, $3.2 \%$ expired sevoflurane is required. After the trachea was intubated, the concentration of expired sevoflurane was adjusted to 1.5 MAC. Patients were ventilated to maintain the end-tidal concentration of carbon dioxide at $35-40 \mathrm{~mm} \mathrm{Hg}$. Concentrations of inspired and expired anesthetic gas, nitrous oxide and carbon dioxide were monitored using the Smart Anesthesia Multi-gas Module (GE Marquette Medical Systems, Tokyo, Japan).

$\mathrm{BP}$ was measured at the supine position during anesthesia. When a patient showed hypertension (SBP $\geqslant 180 \mathrm{~mm} \mathrm{Hg}$ ), subsequent manipulations were temporarily discontinued; if sustained hypertension was observed (all three consecutive BP measurements performed at $1 \mathrm{~min}$ intervals showed a SBP $\geqslant 180 \mathrm{~mm} \mathrm{Hg}$ ), calcium antagonists (nicardipine hydrochloride or diltiazem) were applied. When a patient showed hypotension (SBP $\leqslant 80 \mathrm{~mm} \mathrm{Hg}$ ), additional extracellular fluid was applied within a few min; if sustained hypotension was observed (all three consecutive BP measurements performed at $1 \mathrm{~min}$ intervals showed a SBP $\leqslant 80 \mathrm{~mm} \mathrm{Hg}$ ), ephedrine was applied.

PTG waveforms were obtained using APG HeartRater SA-3000P software (Tokyo Iken, Tokyo, Japan) in the supine position. Each PTG was recorded for a $90 \mathrm{~s}$ period on the index finger of either hand where the BP cuff was not attached, and then they were automatically transformed into SDPTG waveforms and analyzed. Non-invasive SBP, DBP and HR were measured using a patient monitor SOLAR 8000 (GE Marquette Medical Systems) and simultaneously recorded with the SDPTG at four time points as follows: before induction of anesthesia (T0), after loss of consciousness (T1), after tracheal intubation (T2) and $30 \mathrm{~min}$ after induction (T3). Parameters of T0 were recorded immediately after an electrocardiogram, and a BP cuff and a pulse oximetry probe were attached to patients and an i.v. catheter was placed. Parameters of $\mathrm{T} 1$ were recorded after patients lost consciousness by thiopental

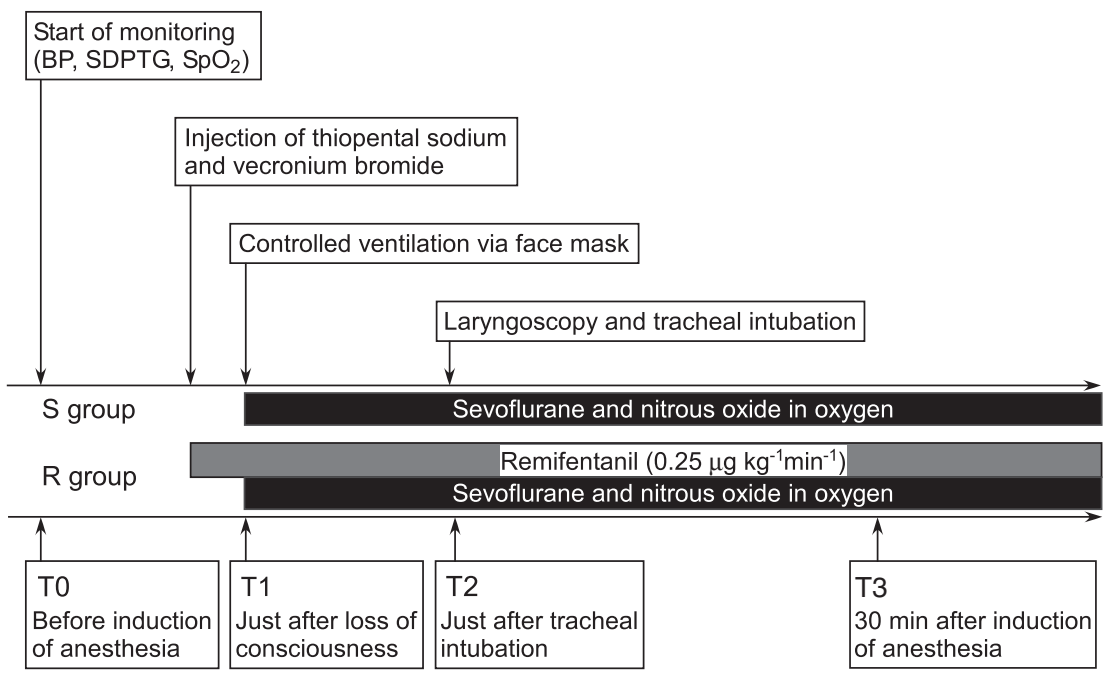

Figure 1 The study protocol is shown. S group, sevoflurane group; R group, sevoflurane with remifentanil group. 


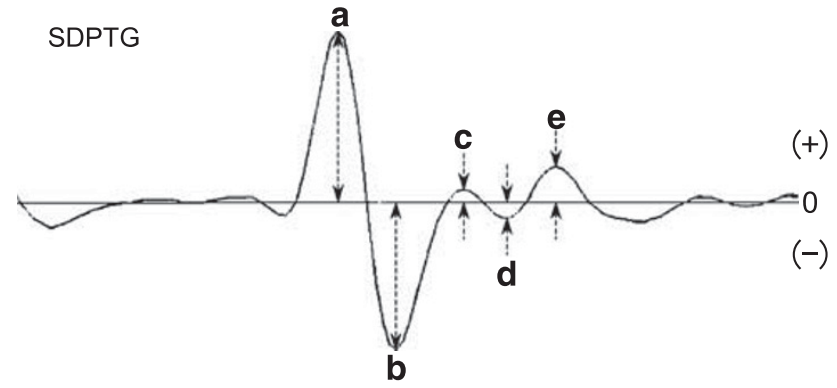

Figure 2 A representative SDPTG recording is shown. The ratios of the height of b-, c- and d-waves to that of the a-wave were measured, with the values above baseline being positive and those under baseline being negative, and they are described as b/a, c/a and d/a.

sodium and then ventilation by face mask was started. Parameters of T2 were recorded just after patients were intubated, both lungs were auscultated, and patients were then mechanically ventilated. Parameters of T3 were recorded $30 \mathrm{~min}$ after induction of anesthesia (that is, application of thiopental sodium and vecuronium bromide). These PTG measurements were carried out when no stimulation was applied to the patients.

Figure 2 shows a representative SDPTG recording. The SDPTG consists of four systolic waves: the a-, b-, c- and d-waves, and a diastolic e-wave. The a-wave (initial positive wave) and b-wave (initial negative wave) correspond to the early systolic component of the PTG, and the c-wave (re-increasing wave) and d-wave (late re-decreasing wave) correspond to the late systolic component. ${ }^{21}$ The $\mathrm{b} / \mathrm{a}$, the ratio of the height of the b-wave to that of the a-wave, expresses the vascular response to blood ejection from the left ventricle and is used as an index of the stiffness of large arteries. The $\mathrm{d} / \mathrm{a}$ represents a reflection wave from the periphery and is used as an index of peripheral vascular resistance or left ventricular after-load. ${ }^{6}$ The AGI, which is defined as the equation of (b-c-d-e)/a, is associated with atherosclerotic alterations, which are based on the history of coronary heart disease, peripheral vascular disease, stroke or abdominal aortic aneurysm, and therefore, it is used as an index of vascular aging. ${ }^{1}$ However, the clinical significance of $c / a$ is not well understood. ${ }^{7}$ The shift from baseline to the peak of each wave was measured and calculated in the software, and was shown as b/a, c/a and d/a. The AGI was also calculated automatically.

\section{Statistical analysis}

Data are expressed as means with s.d. One-way analysis of variance was used to test significance between the two groups for each time point (T0-T3). The Wilcoxon signed-rank test was used to test significance $v s$. control values for each group. The $\chi^{2}$ test was used to test significance between the two groups for gender. Correlations between preanesthetic SDPTG indices $(X)$ and BP after tracheal intubation $(Y)$ were analyzed by Pearson's correlation coefficient, and relations were fitted by simple regression. $P<0.05$ was considered statistically significant.

Receiver operating characteristics curve analysis was performed to identify values of preanesthetic SDPTG indices for optimal discrimination of patients showing a SBP (T2) $\geqslant 180 \mathrm{~mm} \mathrm{Hg}$ or DBP (T2) $\geqslant 110 \mathrm{~mm} \mathrm{Hg}$. Linear discriminant analysis is a predictive model that generates a function based on linear combinations of the predictor variables. Linear discriminant analysis was also applied to discriminate patients showing a SBP (T2) $\geqslant 180 \mathrm{~mm} \mathrm{Hg}$ or DBP (T2) $\geqslant 110 \mathrm{~mm} \mathrm{Hg}$ using combinations of age, preanesthetic BP or preanesthetic SDPTG indices (b/a (T0), d/a (T0) or AGI (T0)) as predictor variables. The variables were chosen stepwise based on the Fisher-Snedecor parameter $F$, by which the variable that makes the largest contribution to the separation of the groups at each step was determined as the discriminant function. The discriminant ability was assessed by the percentage of correct classifications attained for each set. The quality of the discriminate function was evaluated using the Wilks' parameter $\lambda$. All statistical analysis was performed using JMP 8.0 software (SAS Institute Japan, Tokyo, Japan).
Table 1 Baseline characteristics of patients

\begin{tabular}{|c|c|c|c|}
\hline & $S$ group & $R$ group & $\mathrm{P}$-value \\
\hline Age (years) & $64.8 \pm 16.9$ & $66.6 \pm 11.1$ & NS \\
\hline Gender $(M / F)$ & $9 / 13$ & $14 / 6$ & NS \\
\hline Height $(\mathrm{cm})$ & $156.7 \pm 10.5$ & $159.7 \pm 7.5$ & NS \\
\hline Weight (kg) & $55.5 \pm 11.4$ & $59.2 \pm 9.8$ & NS \\
\hline BMI $\left(\mathrm{kg} \mathrm{m}^{-2}\right)$ & $22.4 \pm 3.3$ & $23.2 \pm 3.1$ & NS \\
\hline $\mathrm{SBP}(\mathrm{mm} \mathrm{Hg})$ & $128.4 \pm 17.0$ & $115.8 \pm 12.3$ & NS \\
\hline $\mathrm{DBP}(\mathrm{mm} \mathrm{Hg})$ & $76.2 \pm 8.8$ & $73.2 \pm 9.8$ & NS \\
\hline Hypertensive patients & $15(68 \%)$ & $15(75 \%)$ & NS \\
\hline Diabetes mellitus & $4(18 \%)$ & $5(25 \%)$ & NS \\
\hline Hyperlipidemia & $9(41 \%)$ & $7(35 \%)$ & NS \\
\hline Current or past smoker & $6(27 \%)$ & $8(40 \%)$ & NS \\
\hline Fasting plasma glucose $\left(\mathrm{gdl}^{-1}\right)$ & $104.7 \pm 24.1$ & $120.7 \pm 34.9$ & NS \\
\hline Triglyceride $\left(\mathrm{mg} \mathrm{dl}^{-1}\right)^{\mathrm{a}}$ & $123.6 \pm 71.5$ & $127.4 \pm 74.3$ & NS \\
\hline Total cholesterol $\left(\mathrm{mg} \mathrm{dl}^{-1}\right)$ & $208.9 \pm 39.3$ & $190.2 \pm 37.5$ & NS \\
\hline BUN (mg dl-1) & $15.4 \pm 4.1$ & $17.4 \pm 12.6$ & NS \\
\hline Serum creatinine (mg dl-1) & $0.74 \pm 0.22$ & $1.18 \pm 1.98$ & NS \\
\hline Antihypertensive medication use (\%) & $11(50 \%)$ & $12(60 \%)$ & NS \\
\hline $\mathrm{Ca}^{2+}$ antagonists & 8 & 10 & \\
\hline ARBs & 4 & 6 & \\
\hline ACE inhibitors & 1 & 0 & \\
\hline Lipid medication use (\%) & $5(23 \%)$ & $5(25 \%)$ & NS \\
\hline
\end{tabular}

Abbreviations: $\mathrm{ACE}$, angiotensin-converting enzyme; ARBs, angiotensin II receptor blockers; BMI, body mass index; BUN, blood urea nitrogen; DBP, diastolic blood pressure; NS, not significant; SBP, systolic blood pressure.

$\mathrm{S}$ group, sevoflurane group; $\mathrm{R}$ group, sevoflurane with remifentanil group.

aTriglyceride data were 92 (95.75) in the S group and 116.5 (72) in the R group, in median (interquartile range).

\section{RESULTS}

Three patients were excluded from the data analysis because of use of ephedrine (two patients in the R group), and unstable PTG waveform during the recording period (one patient in the $\mathrm{R}$ group). The total number of cases included in the data analysis was 42 ; the $S$ group had 22 patients and the $\mathrm{R}$ group had 20 patients. The baseline patient characteristics are shown in Table 1.

At T0 and T1, there were no significant differences in SBP and DBP between the two groups. However, both SBP and DBP in the S group were significantly increased at $\mathrm{T} 2$ and those of the $\mathrm{R}$ group were slightly decreased (Figures $3 \mathrm{a}$ and $\mathrm{b} ; P<0.01$ ). At T3, SBP in the $\mathrm{S}$ group was decreased to the same level, whereas DBP was significantly decreased $(P<0.05)$, as compared with those in the R group. Similarly, $\mathrm{HR}$ in the $\mathrm{S}$ group at $\mathrm{T} 2$ was significantly increased compared with that in the $\mathrm{R}$ group (Figure 3c; $P<0.05$ ).

There were no significant differences in $\mathrm{b} / \mathrm{a}$ between the two groups at $\mathrm{T} 0$ and $\mathrm{T} 1$. After tracheal intubation, b/a was significantly elevated in the $\mathrm{S}$ group at T2 compared with that at T0 $(P<0.01)$, showing significant difference compared with the $\mathrm{R}$ group (Figure $4 \mathrm{a} ; P<0.05$ at $\mathrm{T} 2$ ).

No significant differences were observed in $d / a$ between the two groups at $\mathrm{T} 0$ and $\mathrm{T} 1$. In the $\mathrm{S}$ group, $\mathrm{d} / \mathrm{a}$ was significantly reduced at T2 vs. T0 $(P<0.01)$ whereas it was constant in the $\mathrm{R}$ group, showing significant difference compared with the $\mathrm{R}$ group (Figure $4 \mathrm{~b}$; $P<0.05)$. In the $\mathrm{S}$ group, $\mathrm{d} / \mathrm{a}$ was still decreased at $\mathrm{T} 3$ compared with that at T0 $(P<0.01)$, but no significant difference was found between the two groups.

For AGI, there were no significant differences between the two groups at $\mathrm{T} 0$ and $\mathrm{T} 1$. After tracheal intubation, AGI was significantly elevated vs. T0 $(P<0.01$ at T2 and T3) in the $\mathrm{S}$ group, showing significant difference between the two groups (Figure $4 c ; P<0.05$ at T2). 

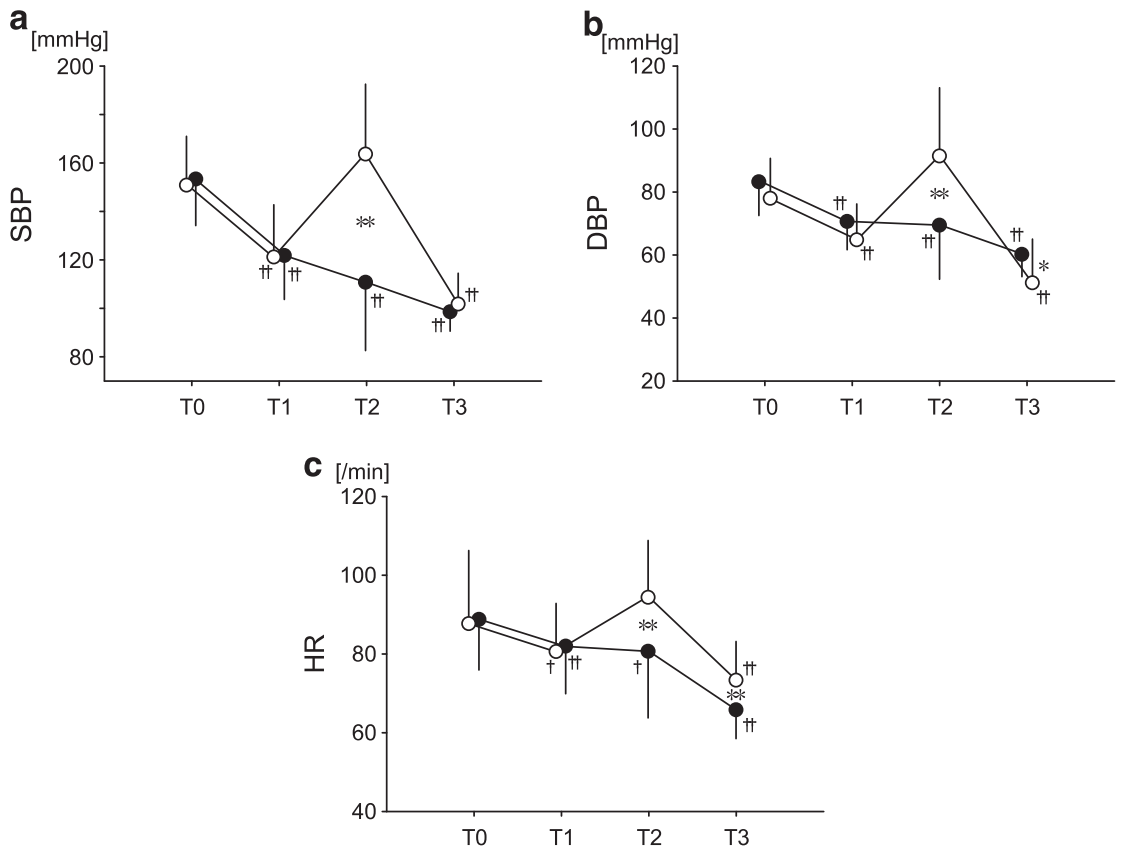

Figure 3 Time course of systolic blood pressure (SBP) (a), diastolic blood pressure (DBP) (b) and heart rate (HR) (c) in the sevoflurane group (S group; open circles) and the sevoflurane with remifentanil group (R group; closed circles). T0, before induction of anesthesia; T1, after loss of consciousness; T2, after tracheal intubation and T3, $30 \mathrm{~min}$ after induction of anesthesia. Data represent mean and s.d. ${ }^{*} P<0.05$ and ${ }^{* *} P<0.01$ compared between groups; ${ }_{\dagger} P<0.05$ and ${ }^{\dagger} P<0.01$ compared with the TO value.
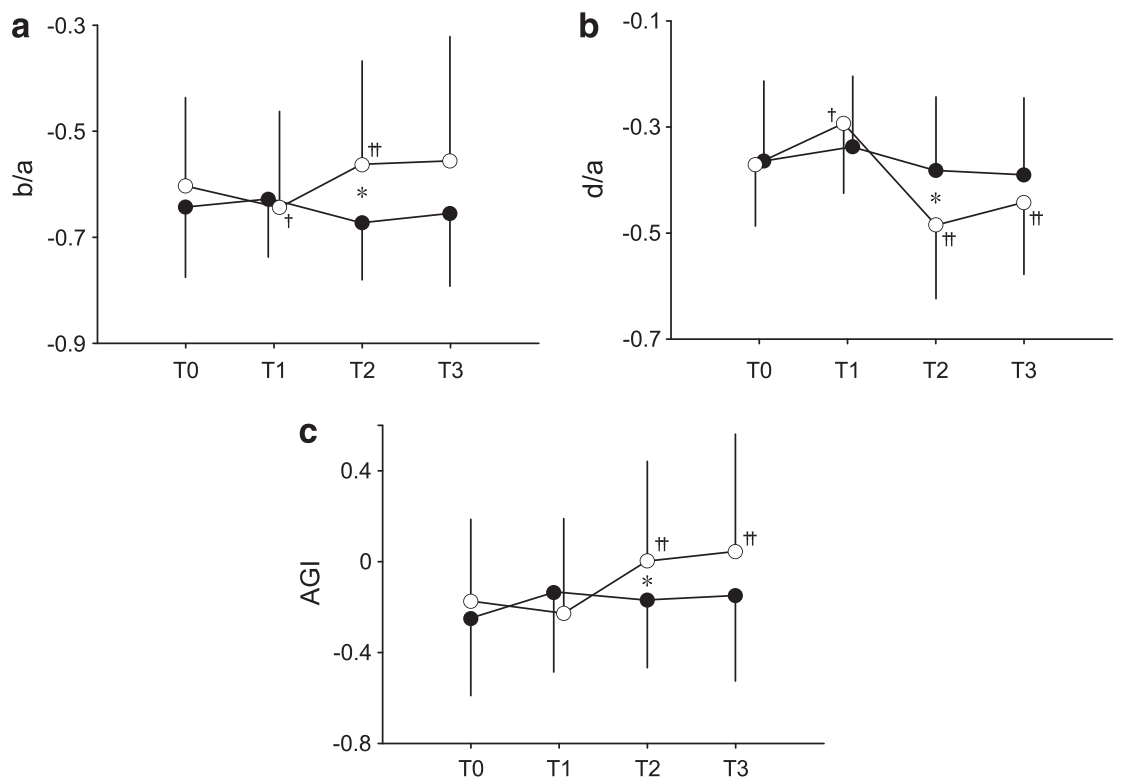

Figure 4 Time course of b/a (a), d/a (b) and SDPTG aging index (AGI) (c) in the sevoflurane group (S group; open circles) and the sevoflurane with remifentanil group (R group; closed circles). T0, before induction of anesthesia; T1, after loss of consciousness; T2, after tracheal intubation and T3, 30 min after induction of anesthesia. Data represent mean and s.d. ${ }^{*} P<0.05$ compared between groups; ${ }^{\dagger} P<0.05$ and ${ }^{\dagger \dagger} P<0.01$ compared with the T0 value.

Relationships between preanesthetic SDPTG indices and SBP after tracheal intubation in the $S$ group are shown in Figure 5. The higher the b/a (T0) and AGI (T0), the higher the SBP (T2), with strong correlation coefficients $(R=0.65$ and 0.69 , respectively $)$ and significant correlations $(P<0.01$ and 0.001 , respectively; Figures $5 \mathrm{a}$ and $\mathrm{c})$. The d/a (T0) showed a significant, negative relationship with SBP (T2) $(P<0.0001)$ with a strong correlation coefficient $(R=-0.74$; Figure $5 b$ ). Similarly, DBP (T2) had a significant, positive relation- ship with b/a (T0) and a negative relationship with d/a (T0) $(P<0.05$ and 0.001 , respectively), with notable correlation coefficients $(R=0.50$ and -0.68 , respectively). The AGI (T0) showed a positive relationship with DBP (T2) with a notable correlation coefficient $(R=0.57)$, whereas the relationship was not significant $(P=0.0052)$.

Figure 6 shows receiver operating characteristic curves of b/a (T0), $\mathrm{d} / \mathrm{a}$ (T0) and AGI (T0) to predict a SBP (T2) $\geqslant 180 \mathrm{~mm} \mathrm{Hg}$ or DBP $(\mathrm{T} 2) \geqslant 110 \mathrm{~mm} \mathrm{Hg}$. The area under the receiver operating character- 
a

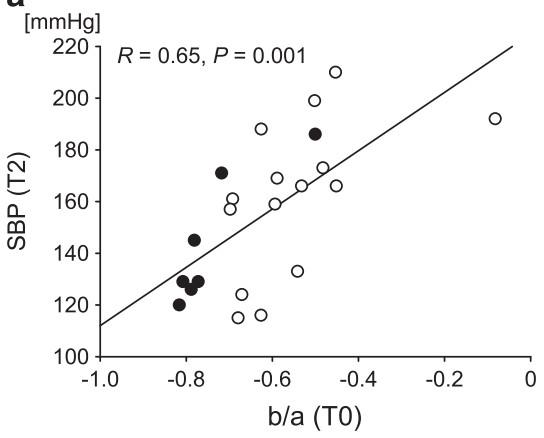

b

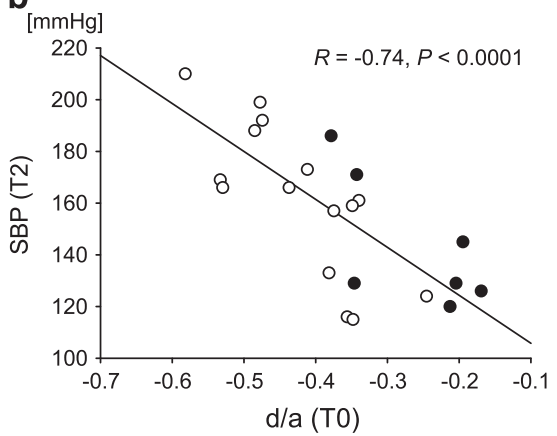

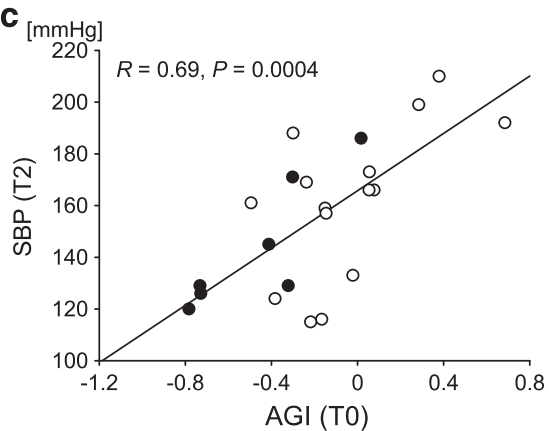

Figure 5 Relationships between systolic blood pressure (SBP) at T2 and b/a (a), d/a (b) and AGI (c) at T0 in the sevoflurane group (S group). Patients with a history of hypertension or hypertensive factors are shown by open circles, and those without a history of hypertension or hypertensive factors are shown by closed circles. The regression line shows the results of simple regression fitting for all cases. $R$ indicates Pearson's correlation coefficient. T0, before induction of anesthesia; T2, after tracheal intubation.

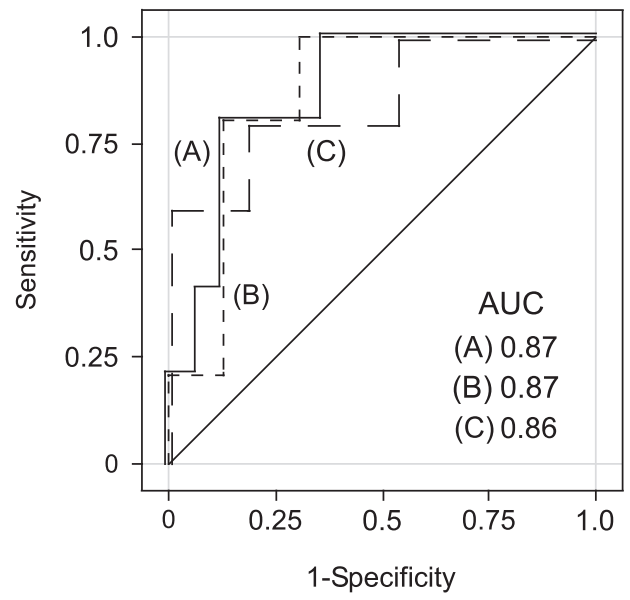

Figure 6 Receiver operating characteristic (ROC) curves of the ability of $\mathrm{b} / \mathrm{a}$ (A) (solid line), d/a (B) (chain line) and AGI (C) (dashed line) at T0 to predict SBP (T2) $\geqslant 180 \mathrm{~mm} \mathrm{Hg}$ or DBP (T2) $\geqslant 110 \mathrm{~mm} \mathrm{Hg}$ in the sevoflurane group (S group). AUC, area under the ROC curve. TO, before induction of anesthesia; T2, after tracheal intubation.

istic curve (AUC) for b/a (T0) was 0.87 , with a peak discriminating sensitivity and specificity of 0.80 and 0.88 , respectively, where the cutoff point of b/a was -0.50 . The AUC for $\mathrm{d} / \mathrm{a}$ (T0) was 0.87 , with a peak discriminating sensitivity and specificity of 1.00 and 0.71 , respectively, where the cutoff point of $\mathrm{d} / \mathrm{a}$ was -0.38 . The AUC for AGI (T0) was 0.86 , with a peak discriminating sensitivity and specificity of 0.80 and 0.82 , respectively, where the cutoff point of AGI was 0.02 .
Table 2 Application of LDA to predict a SBP (T2) $\geqslant 180 \mathrm{~mm} \mathrm{Hg}$ or DBP (T2) $\geqslant 110 \mathrm{~mm} \mathrm{Hg}$ using predictor variables in the $S$ group

\begin{tabular}{lcccccc}
\hline Number of predictor variables & 1 & 2 & 3 & 4 & 5 & 6 \\
\hline AGI (TO) & Yes & Yes & Yes & Yes & Yes & Yes \\
Age (years) & No & Yes & Yes & Yes & Yes & Yes \\
b/a (TO) & No & No & Yes & Yes & Yes & Yes \\
SBP (TO) & No & No & No & Yes & Yes & Yes \\
d/a (TO) & No & No & No & No & Yes & Yes \\
DBP (TO) & No & No & No & No & No & Yes \\
Wilks' $\lambda$ & 0.644 & 0.579 & 0.558 & 0.539 & 0.515 & 0.511 \\
Correct classification & 17 & 20 & 20 & 20 & 17 & 18 \\
(out of 22 cases) & & & & & & \\
Correct classification rate (\%) & 77.3 & 90.9 & 90.9 & 90.9 & 77.3 & 81.8 \\
\hline
\end{tabular}

Abbreviations: AGI, aging index; DBP, diastolic blood pressure; LDA, linear discriminant analysis; SBP, systolic blood pressure.

The predictor variables were shown as an order of stepwise choice based on the Fisher-Snedecor parameter F. S group, sevoflurane group; TO, before induction of anesthesia; T2, after tracheal intubation.

The results of linear discriminant analysis applied to discriminating patients showing a SBP (T2) $\geqslant 180 \mathrm{~mm} \mathrm{Hg}$ or DBP (T2) $\geqslant 110 \mathrm{~mm} \mathrm{Hg}$ using predictor variables in the $\mathrm{S}$ group are shown in Table 2. Usage of AGI (T0), age, b/a (T0) and SBP (T0) as predictor variables effectively classified patients showing hypertension in response to laryngoscopy and tracheal intubation.

\section{DISCUSSION}

The onset of action of remifentanil is rapid, and therefore, it effectively attenuates cardiovascular responses to noxious stimuli, such as laryngoscopy, tracheal intubation or surgical manipulation. ${ }^{22}$ The current 
study showed that sevoflurane, in the absence of remifentanil, caused an elevation of $b / a$ and reduction of $d / a$, as well as an increase in both BP and HR after tracheal intubation. On the other hand, the application of remifentanil in combination with sevoflurane suppressed the elevation of $\mathrm{b} / \mathrm{a}$ and reduction of $\mathrm{d} / \mathrm{a}$, as well as the increase in BP and HR. Therefore, this suggested that sevoflurane was unable to suppress an increase in sympathetic tone (increased BP and $\mathrm{HR}$ ) and sympathetically mediated peripheral vasoconstriction (reduced $\mathrm{d} / \mathrm{a}$ ) in response to tracheal intubation; therefore, the vascular response to blood ejection from the left ventricle was increased (elevated b/a). Remifentanil inhibited sympathetically mediated contraction of peripheral blood vessels and decreased after-load of the left ventricle in response to tracheal intubation. These findings are consistent with previous findings that remifentanil induces bradycardia and hypotension ${ }^{23-25}$ due to a reduction in peripheral vascular resistance and the cardiac index, ${ }^{26}$ and that the hemodynamic instability of remifentanil is mediated by stimulation of cardiac parasympathetic nerve, as well as a direct effect on peripheral vascular tone. ${ }^{17}$ Our results also suggest that the SDPTG indices, b/a, d/a and AGI, reflect peripheral vascular resistance and a response of large vessels to increased cardiac output during induction of anesthesia.

Furthermore, our results suggest that there are significant relationships between preanesthetic SDPTG indices and BP in response to laryngoscopy and tracheal intubation under sevoflurane anesthesia. Because b/a expresses vascular responses to blood ejection from the left ventricle and $\mathrm{d} / \mathrm{a}$ reflects peripheral vascular resistance, it was reasonable that preanesthetic b/a was correlated with SBP and preanesthetic d/a was correlated with DBP at immediate postintubation. Moreover, the current results suggest that combinations of predictor variables are capable of predicting hypertension in anesthesia induction, regardless of a history of hypertension or hypertensive factors. Among these variables, age is an important factor affecting aortic stiffness; SBP is influenced by the stiffness of large arteries, ${ }^{27}$ and SBP continues to rise until the eighth or ninth decade. ${ }^{28}$

Our findings suggested that vascular aging-like mechanisms, which include increased arterial stiffness and increased peripheral vascular resistance, ${ }^{6}$ occurred during induction of sevoflurane anesthesia. This finding is considered to be mainly due to increased cardiac sympathetic nerve activity. The increase in sympathetic activity was especially applicable to patients with a history of hypertension or hypertensive factors; categorized wave patterns of hypertensive patients in the $S$ group shifted to aged patterns at T2 and T3, while this shift was prevented in the presence of remifentanil (data not shown). Therefore, we consider that it is reasonable to stimulate cardiac parasympathetic nerve and reduce peripheral vascular resistance by means of remifentanil in patients with hypertension. There was a significant difference in AGI in response to laryngoscopy and tracheal intubation between the two groups. This finding suggests that this index, which generally represents atherosclerosis and is used as a parameter of vascular aging, is also susceptible to stress during anesthesia induction, and thus reflects properties of the vascular wall, independent of hemodynamic changes.

A recent study using preoperative carotid-femoral pulse wave velocity failed to predict hemodynamic responses to anesthesia and surgical stimulation. ${ }^{16}$ It is possible that the reasons for this failure could be that pulse wave velocity solely indicates aortic stiffness but not left ventricular after-load or peripheral vascular resistance, and that the patients enrolled were relatively young and of the female gender, who have lower BP than middle age or older patients, or males. ${ }^{28}$ However, in our preliminary findings where young patients in the second or third decade were included, an increase in b/a and/or a decrease in $\mathrm{d} / \mathrm{a}$ were not typically observed, even during sevoflurane anesthesia. Therefore, prediction of hypertension using SDPTG indices is suitable for aged subjects who may possibly have atherosclerotic change.

In this study, we used the definition of hypertension during anesthesia induction as SBP $\geqslant 180 \mathrm{~mm} \mathrm{Hg}$ or DBP $\geqslant 110 \mathrm{~mm} \mathrm{Hg}$, which is based on stage 3 hypertension in the report of the Joint National Committee on Prevention, Detection, Evaluation and Treatment of High Blood Pressure (the JNC sixth report). ${ }^{29}$ There is no definite description of hypertension and/or hypotension during the perioperative period, except for 'acceptable values for cardiovascular variables during and after surgery', where SBP is within the range of $85-175 \mathrm{~mm} \mathrm{Hg},{ }^{30}$ or it has been described that postoperative hypertension is 'arbitrarily' defined as a SBP $\geqslant 190 \mathrm{~mm} \mathrm{Hg}$ and/or DBP $\geqslant 100 \mathrm{~mm} \mathrm{Hg}$ following surgery. ${ }^{31}$ Second, we should note that the findings of this study should be interpreted in view of a limitation that family history of cardiovascular diseases has not been considered to determine hypertensive factors.

In conclusion, our findings suggest that usage of remifentanil, a potent $\mu$-opioid analgesic, to sevoflurane anesthesia prevents an increase in BP and HR in response to laryngoscopy and tracheal intubation, which is accompanied by suppression of both elevation of $\mathrm{b} / \mathrm{a}$ and AGI and reduction of d/a. Sub-analysis of the data also suggested that the SDPTG indices are useful for predicting hypertension (SBP $\geqslant 180 \mathrm{~mm} \mathrm{Hg}$ or DBP $\geqslant 110 \mathrm{~mm} \mathrm{Hg}$ ) during induction of sevoflurane anesthesia in patients aged $\geqslant 40$, regardless of a history of hypertension or hypertensive factors.

\section{CONFLICT OF INTEREST}

The authors declare no conflict of interest.

\section{ACKNOWLEDGEMENTS}

This work was supported solely by the institutional resources.

1 Bortolotto LA, Blacher J, Kondo T, Takazawa K, Safar ME. Assessment of vascular aging and atherosclerosis in hypertensive subjects: second derivative of photoplethysmogram versus pulse wave velocity. Am J Hypertens 2000; 13: 165-171.

2 Blacher J, Asmar R, Djane S, London GM, Safar ME. Aortic pulse wave velocity as a marker of cardiovascular risk in hypertensive patients. Hypertension 1999; 33: 1111-1117.

3 Laurent S, Boutouyrie P, Asmar R, Gautier I, Laloux B, Guize L, Ducimetiere P, Benetos A. Aortic stiffness is an independent predictor of all-cause and cardiovascular mortality in hypertensive patients. Hypertension 2001; 37: 1236-1241.

4 Cruickshank K, Riste L, Anderson SG, Wright JS, Dunn G, Gosling RG. Aortic pulsewave velocity and its relationship to mortality in diabetes and glucose intolerance: an integrated index of vascular function? Circulation 2002; 106: 2085-2090.

5 Dolan E, Thijs L, Li Y, Atkins N, McCormack P, McClory S, O'Brien E, Staessen JA, Stanton AV. Ambulatory arterial stiffness index as a predictor of cardiovascular mortality in the Dublin Outcome Study. Hypertension 2006; 47: 365-370.

6 Otsuka T, Kawada T, Katsumata M, Ibuki C. Utility of second derivative of the finger photoplethysmogram for the estimation of the risk of coronary heart disease in the general population. Circ J 2006; 70: 304-310.

7 Takazawa K, Tanaka N, Fujita M, Matsuoka O, Saiki T, Aikawa M, Tamura S, Ibukiyama C. Assessment of vasoactive agents and vascular aging by the second derivative of photoplethysmogram waveform. Hypertension 1998; 32: 365-370.

8 Hashimoto J, Watabe D, Kimura A, Takahashi H, Ohkubo T, Totsune K, Imai Y. Determinants of the second derivative of the finger photoplethysmogram and brachialankle pulse-wave velocity: the Ohasama study. Am J Hypertens 2005; 18: 477-485.

9 Takada $\mathrm{H}$, Washino K, Harrell JS, Iwata $\mathrm{H}$. Acceleration plethysmography to evaluate aging effect in cardiovascular system. Using new criteria of four wave patterns. Med Prog Technol 1996; 21: 205-210.

10 Kovac AL. Controlling the hemodynamic response to laryngoscopy and endotracheal intubation. J Clin Anesth 1996; 8: 63-79.

11 Roy WL, Edelist G, Gilbert B. Myocardial ischemia during non-cardiac surgical procedures in patients with coronary-artery disease. Anesthesiology 1979; 51: 393-397.

12 Kleinman B, Henkin RE, Glisson SN, el-Etr AA, Bakhos M, Sullivan HJ, Montoya A Pifarre R. Qualitative evaluation of coronary flow during anesthetic induction using thallium-201 perfusion scans. Anesthesiology 1986; 64: 157-164. 
13 Giles RW, Berger HJ, Barash PG, Tarabadkar S, Marx PG, Hammond GL, Geha AS, Laks $\mathrm{H}$, Zaret $\mathrm{BL}$. Continuous monitoring of left ventricular performance with the computerized nuclear probe during laryngoscopy and intubation before coronary artery bypass surgery. Am J Cardiol 1982; 50: 735-741.

14 Slogoff S, Keats AS. Does perioperative myocardial ischemia lead to postoperative myocardial infarction? Anesthesiology 1985; 62: 107-114.

15 Obara S, Imaizumi T, Ohashi S, Nakano Y, Takahashi S, Hayashi S, lida H, Akatsu M, Isosu T, Murakawa M. Preoperative second-derivative of photoplethysmography measurement predicts the hemodynamic response to general anaesthesia induction. Masui 2009; 58: 1488-1495.

16 Nakata Y, Goto T, Ishiguro Y, Terui K, Niimi Y, Morita S. Preoperative pulse wave velocity fails to predict hemodynamic responses to anesthesia and to surgical stimulation. J Clin Anesth 1999; 11: 285-289.

17 Noseir RK, Ficke DJ, Kundu A, Arain SR, Ebert TJ. Sympathetic and vascular consequences from remifentanil in humans. Anesth Analg 2003; 96: 1645-1650.

18 Keats AS. The ASA classification of physical status-a recapitulation. Anesthesiology 1978; 49: 233-236.

19 Katoh T, Ikeda K. The minimum alveolar concentration (MAC) of sevoflurane in humans. Anesthesiology 1987; 66: 301-303.

20 Mapleson WW. Effect of age on MAC in humans: a meta-analysis. Br J Anaesth 1996; 76: 179-185.

21 Takazawa K, Fujita M, Yabe K, Sakai T, Kobayashi T, Maeda K, Yamashita Y, Hase M, Ibukiyama C. Clinical usefulness of the second derivative of a plethysmogram (acceleration plethysmogram). J Cardiol 1993; 23(Suppl 37): 207-217.
22 Habib AS, Parker JL, Maguire AM, Rowbotham DJ, Thompson JP. Effects of remifentanil and alfentanil on the cardiovascular responses to induction of anaesthesia and tracheal intubation in the elderly. Br J Anaesth 2002; 88: 430-433.

23 DeSouza G, Lewis MC, TerRiet MF. Severe bradycardia after remifentanil. Anesthesiology 1997; 87: 1019-1020.

24 Reid JE, Mirakhur RK. Bradycardia after administration of remifentanil. Br J Anaesth 2000; 84: 422-423.

25 Sebel PS, Hoke JF, Westmoreland C, Hug Jr CC, Muir KT, Szlam F. Histamine concentrations and hemodynamic responses after remifentanil. Anesth Analg 1995; 80: 990-993.

26 Elliott P, O'Hare R, Bill KM, Phillips AS, Gibson FM, Mirakhur RK. Severe cardiovascular depression with remifentanil. Anesth Analg 2000; 91: 58-61.

27 Oliver JJ, Webb DJ. Noninvasive assessment of arterial stiffness and risk of atherosclerotic events. Arterioscler Thromb Vasc Biol 2003; 23: 554-566.

28 Franklin SS, Gustin Wt, Wong ND, Larson MG, Weber MA, Kannel WB, Levy D. Hemodynamic patterns of age-related changes in blood pressure. The Framingham Heart Study. Circulation 1997; 96: 308-315.

29 The sixth report of the Joint National Committee on prevention, detection, evaluation, and treatment of high blood pressure. Arch Intern Med 1997; 157: 2413-2446.

30 Miller RD (ed). Anesthesia. 5th edn Churchill Livingstone: Philadelphia, 2002, pp. 903-1016.

31 Varon J, Marik PE. Clinical review: the management of hypertensive crises. Crit Care 2003; 7: 374-384. 